Journal of

Accident and

Emergency

Medicine 1993

11, 53-54
Correspondence:

Miss L. Roberts, Royal Sussex County Hospital, Eastern Road, Brighton, East Sussex

CASE REPORT

\title{
Survival following intentional massive overdose of 'Ecstasy'
}

\author{
L. ROBERTS \& H.WRIGHT
}

Accident and Emergency Department, Royal Sussex County Hospital, Eastern Road, Brighton, East Sussex

\section{SUMMARY}

A case of intentional overdose with 18 'Ecstasy' tablets is described. 'Ecstasy' is a semi-synthetic hallucinogenic amphetamine and acute adverse reactions follow from the effects of sympathetic stimulation. To our knowledge this is the first reported case of massive intentional overdose reported in the literature.

Key words: acute adverse reactions, dantrolene, MDMA.

\section{INTRODUCTION}

'Ecstasy' (3,4-methylenedioxymetamphetamine MDMA) is now a popular recreational drug. Fatalaties have been reported after taking just one tablet due to an idiosyncratic reaction to MDMA. Such deaths are usually the result of cardiac dysrhythmias.

\section{CASE REPORT}

A 20-year-old man was admitted to the accident and emergency (A\&E) department $34 \mathrm{~min}$ after taking 18 'Ecstasy' tablets preceded by at least 5 pints of beer. At home, within minutes of ingestion, his behaviour was noted to be abnormal and an ambulance was called.

On arrival in A\&E he was sweating profusely, vomiting and was very irritable. Within minutes he developed marked trismus and began convulsing. It became difficult to maintain his airway and his $\mathrm{SaO}_{2}$ was $60 \%$ and falling. Rapid sequence induction with etomidate and suxamethonium was performed.

His core temperature was $38.6^{\circ} \mathrm{C}$ on admission and $60 \mathrm{mg}$ dantrolene was administered. He was cooled actively by sponging and his stomach was washed out via a nasogastric tube with cold water. A further $40 \mathrm{mg}$ of Dantrolene was administered and when his temperature came down to $36.9^{\circ} \mathrm{C}$ active cooling was stopped.

The patient was rehydrated with Hartman's solution (21) and normal saline and was catheterized. He was admitted to the intensive therapy unit, sedated and ventilated for $48 \mathrm{~h}$. He was treated with antibiotics, a further dose of dantrolene and he required active cooling while on the unit. $\mathrm{He}$ was extubated $48 \mathrm{~h}$ later. He took his own discharge the following day. One week later he was fully recovered although admitted to being forgetful, irritable and having flashbacks to events immediately prior to losing consciousness.

\section{RESULTS}

The patient's urea and electrolytes, liver function tests and clotting studies were normal. Plasma MDMA concentration was $4.05 \mathrm{mgl}^{-1}$ (severe toxicity indicated by a value greater than $0.2 \mathrm{mgl}^{-1}$ ). Blood alcohol was $1.2 \mathrm{gl}^{-1}$. Urinary myoglobin was negative.

\section{DISCUSSION}

With the increased popularity and availability of 'Ecstasy' A\&E departments are inevitably going to be exposed to treating patients with similar drug related problems ${ }^{1,2}$. One of the potential problems we have encountered is the availability of dantrolene. It has a relatively short shelf-life of 1 year, can only be ordered in 12 vial packs and was used infrequently within the hospital. As such it was not stocked in adequate quantities. After consultation with our pharmacy we have now increased hospital stock.

Moderate toxicity with MDMA is indicated by hyperreflexia, hypotension, tachypnoea and visual hallucinations. Severe toxicity presents with coma, convulsions, arrhythmias, rigidity, rhabdomyolysis, acute renal failure, disseminated intravascular 
L. Roberts \& $H$. Wright coagulation, metabolic acidosis, adult respiratory distress syndrome and intracerebral haemorrhage.

Creatinine phosphokinase (CPK), potassium and blood sugar should be monitored, together with renal and liver function. Disseminated intravascular coagulation (D.I.C.) and metabolic acidosis should be corrected accordingly. An idiosyncratic reaction to MDMA is indicated by increased muscle tone, trismus, dilated pupils, tachycardia and nystagmus. We appreciate in retrospect that in the circumstances suxamethonium should not have been our drug of first choice for paralysing the patient. The paralysing drug of choice is atracurium.

\section{ACKNOWLEDGEMENTS}

We wish to thank staff at Guy's Poison Laboratory for their advice on management and toxicological analysis.

\section{REFERENCES}

1. Curry P.D., Chadwick I.S., Linsley A., Freemont A.J. \& Doran B. (1991) Ecstasy (3,4-methylenedioxymetamphetamine) A fatality associated with coagulopathy and hyperthermia. Journal of the Royal Society of Medicine June, 371.

2. Dowling G.P., McDonough E.T. \& Bost R.O. (1987) Eve and Ecstasy: $A$ report on five deaths associated with the use of MDEA and MDMA. Journal of the American Medical Association 257, 1615-1617. 